\title{
Australian Oryza: Utility and Conservation
}

\author{
Robert J. Henry • Nicole Rice • Daniel L. E. Waters • Shabana Kasem • \\ Ryuji Ishikawa • Yin Hao • Sally Dillon • Darren Crayn • Rod Wing • Duncan Vaughan
}

Received: 1 October 2009 /Accepted: 7 December 2009 / Published online: 30 December 2009

(C) Springer Science+Business Media, LLC 2009

\begin{abstract}
Australian Oryza are an understudied and underexploited genetic resource for rice improvement. Four species are indigenous: Oryza rufipogon, Oryza meridionalis, Oryza australiensis are widespread across northern Australia, whereas Oryza officinalis is known from two localities only. Molecular analysis of these wild populations is required to better define the distinctness of the taxa and the extent of any gene flow between them and rice. Limited
\end{abstract}

R. J. Henry $(\bowtie) \cdot$ N. Rice $\cdot$ D. L. E. Waters $\cdot$ S. Kasem Centre for Plant Conservation Genetics,

Southern Cross University,

P.O. Box 157, Lismore, NSW 2480, Australia

e-mail: robert.henry@scu.edu.au

R. Ishikawa $\cdot$ Y. Hao

Faculty of Agriculture and Life Science, Hirosaki University, Hirosaki, Aomori 036-861, Japan

\section{S. Dillon}

Australian Tropical Crops and Forages Germplasm Centre, Queensland Primary Industries and Fisheries,

Biloela, QLD 4715, Australia

D. Crayn

Australian Tropical Herbarium, James Cook University,

P.O. Box 6811, Cairns, QLD 4870, Australia

R. Wing

Department of Plant Sciences, Arizona Genomics Institute, University of Arizona,

Tucson, AZ 85721, USA

\section{Vaughan}

Food and Agricultural Organization of the United Nations, Regional Office for Asia and the Pacific,

Maliwan Mansion, 39 Phra Atit Road,

Bangkok 10200, Thailand collections of these wild populations are held in seed and DNA banks. These species have potential for domestication in some cases but also have many traits of potential value in the improvement of domesticated rice. Stress tolerance (biotic and abiotic) and grain quality characteristics in these populations may be useful.

Keywords Germplasm · Conservation · Diversity · Wild rice

\section{Introduction}

Rice (Oryza sativa L.) was domesticated in Asia (Vaughan et al. 2008). Asian wild rice populations have coexisted with domesticated rice for a long period with significant potential for gene flow between wild and domesticated rice in both directions. Domesticated rice was introduced to Australia only very recently (in the last 200 years) and has not been grown near many of the wild populations. Production has been mainly in southern New South Wales and Victoria rather than in the tropics. As a result of this genetic isolation, Oryza in Australia may provide important information on the genetics and biology of rice prior to domestication. Australian Oryza species are a diverse and poorly characterized plant group. These populations probably represent an important and underutilized genetic resource for use in rice improvement. Four Oryza species are native to Australia: Oryza meridionalis N.Q.Ng, Oryza rufipogon Griff., Oryza australiensis Domin, and Oryza officinalis Wall. ex G.Watt (Fig. 1). O. sativa is naturalized in some limited areas (possibly shattering forms of $O$. sativa). The Oryzeae tribe in Australia also includes the endemic and monospecific Potamophilia and two Leersia species one of which is native (Leersia hexandra Sw.). 

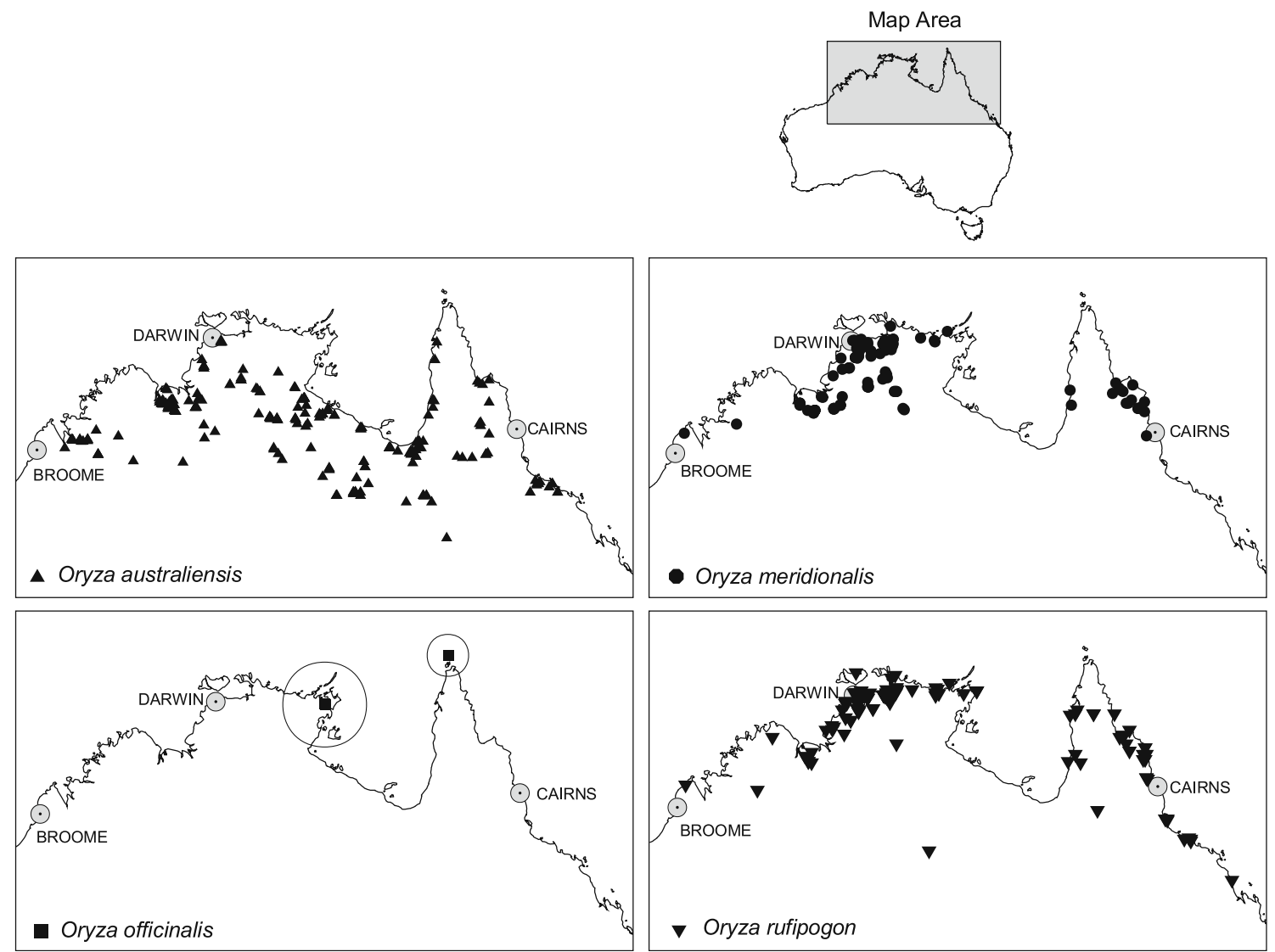

Fig. 1 Distribution of Oryza species in Australia as indicated by Australian Herbarium records.

\section{Taxonomy of Australian Oryza}

The Ehrhartoideae subfamily of the Poaceae includes three tribes and 120 species with two tribes and 18 species including the Oryzeae tribe found in Australia (Table 1).

Table 1 Oryza and Other Members of the Ehrhartoideae Subfamily in Australia (Flora of Australia, Kodela 2009)

\begin{tabular}{|c|c|c|}
\hline Tribe & Genus & Species \\
\hline \multirow[t]{3}{*}{ Oryzeae } & Leersia & $\begin{array}{l}\text { hexandra } \\
\text { oryzoides }^{\mathrm{a}}\end{array}$ \\
\hline & Oryza & $\begin{array}{l}\text { australiensis } \\
\text { officinalis } \\
\text { sativa }^{\mathrm{a}} \\
\text { rufipogon } \\
\text { meridionalis }\end{array}$ \\
\hline & Potamophila & parviflora \\
\hline \multirow[t]{4}{*}{ Ehrhateae } & Ehrharta ${ }^{\mathrm{a}}$ & 6 introduced species \\
\hline & Tetrarrhena & 6 endemic species \\
\hline & Microlaena & stipoides \\
\hline & & tasmanica \\
\hline
\end{tabular}

${ }^{\mathrm{a}}$ Species introduced and naturalized in the Australian environment
Native Oryza species are distributed across northern Australia, typically in monsoonal rainfall wet season areas.

O. rufipogon

O. rufipogon is a native perennial found in wet or swampy locations in northern Australia from Queensland and the Northern Territory to Western Australia. Recent molecular evidence (Hao and Ryuji, unpublished) suggests that the Australian populations of $O$. rufipogon may be distinct from the Asian populations.

\section{O. meridionalis}

O. meridionalis (Fig. 2) is a species that was thought to be endemic to Australia until the recent report of a population in Irian Jaya, Indonesia. This is an annual species that grows in wet areas and survives as seed in the dry season. This species has been reported from Queensland, Northern Territory, and Western Australia. The relationships between $O$. meridionalis and O. rufipogon populations require further investigation to establish the extent to which these populations are genetically distinct especially where they are reported from the same location (Fig. 3). 


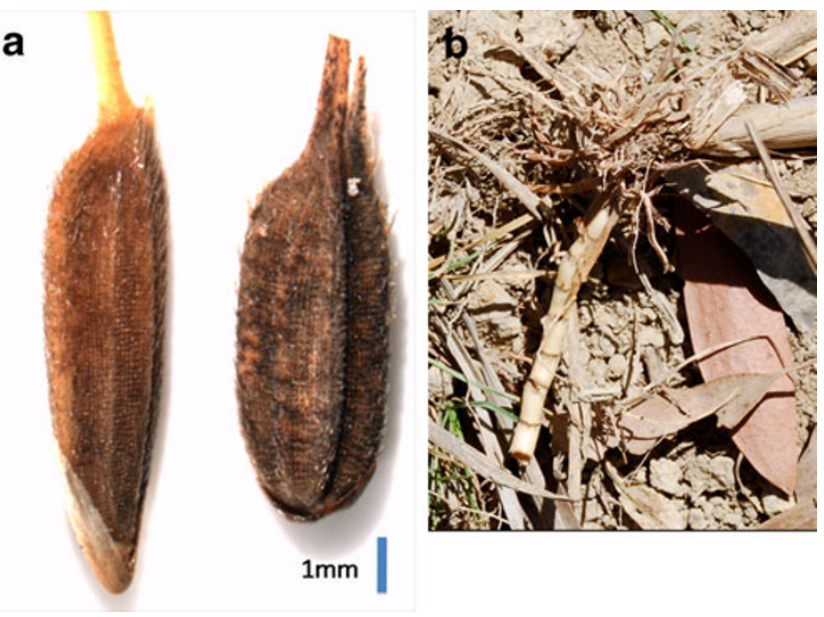

Fig. 2 a $O$. australiensis (right) compared to O. meridionalis (left). b Rhizomes of $O$. australiensis that allow survival in the dry season.

\section{O. australiensis}

O. australiensis (Fig. 2) is an endemic Australian species found across northern Australia in Queensland, Northern Territory, and Western Australia. This is a perennial that grows in relatively dry areas for an Oryza species. It is found in seasonally wet areas and apparently survives the dry season as rhizomes or seeds. This species has the largest genome in the genus due to apparent expansion with retrotransposons which has effectively doubled the genome size (Piegu et al. 2006).

\section{O. officinalis}

$O$. officinalis is a native species that has been reported from only two locations in the north of Queensland and the Northern Territory. The distribution of this species in Australia requires more investigation as it has been found in two remote and poorly collected regions only: Moa Island in Torres Strait and eastern Arnhem Land in the Northern Territory.

\section{Oryza sativa}

Rice has been cultivated in several regions in Australia and has become naturalized in some locations. Plants may also be found near to cultivation in the main production areas in New South Wales but are not likely to become naturalized in these areas. It is not clear if any weedy rice, shattering forms of $O$. sativa, are present.

\section{Oryza nivara}

The status of O. nivara S. D. Sharma \& Shastry in Australia is uncertain (Kodela 2009).

\section{Oryza minuta}

Reports of O. minuta J. Presl. from Australia have probably been due to confusion with $O$. officinalis or other species (Kodela 2009). Further molecular analysis of Australian populations will clarify these reports.

\section{Other related plants in the Australian flora}

\section{Potamophila parviflora}

P. parviflora $\mathrm{R}$. Br. is the sole species of the genus and is restricted to the rivers of northern New South Wales (Abedinia et al. 1998). It has not been reported from Queensland despite being found close to the border. This taxon is apparently more closely related to Zizania than to Oryza based upon ribosomal gene sequence analysis (Abedinia et al. 1998). Furthermore, Potamophila shares with Zizania the possession of separate sex flowers (Wheeler et al. 2001). The seeds are very small but the morphology of the seed is also similar to that of Zizania.

\section{Microlaena stipoides (Labill.) R.Br.}

M. stipoides is a widespread native species found in all states but not in the Northern Territory. Some genotypes of the species have large seeds that may be suitable for consumption as a whole-grain food as an alternative to rice. This species may be suitable for production in colder areas and with much less water than that required for domesticated rice. Attempts to domesticate this species as an alternative to rice that can be grown with less water are currently in progress. The strategy for accelerated domestication of this species involves the use of targeted mutagenesis (Cross et al. 2008) of domestication genes that have been characterized in the rice genome.

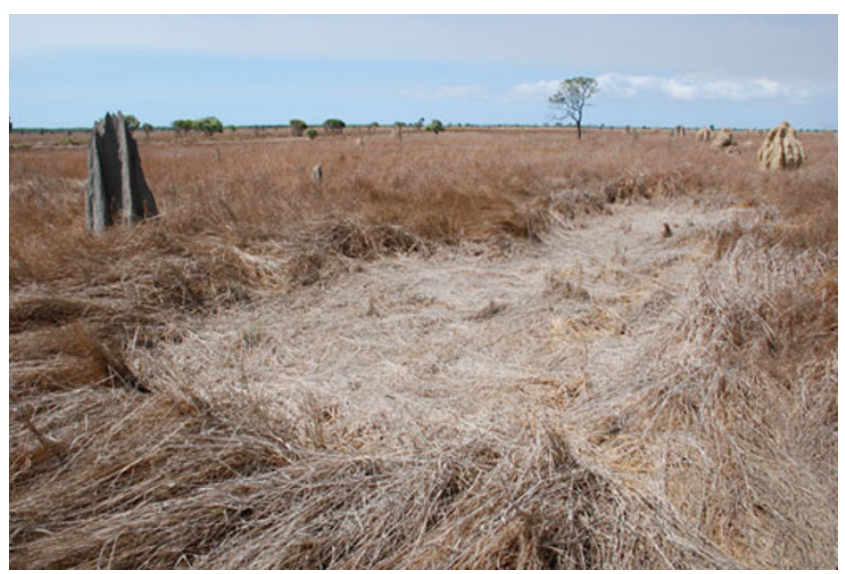

Fig. 3 Wild rice habitat $O$. meridionalis lodged in the dry season at Nifold Plain, Lakefield National Park. 


\section{Progress in characterizing the genomes of Australian Oryza}

Physical maps of the genomes of O. rufipogon (439 Mb), O. officinalis $(651 \mathrm{Mb})$, and $O$. australiensis $(965 \mathrm{Mb})$ have been produced (Kim et al. 2008). Whole shotgun sequencing of $O$. australiensis and $O$. meridionalis has been undertaken recently (Henry et al., unpublished). Assembly of reference genome sequences for these species will await sequencing of bacterial artificial chromosome tiles of these genomes.

\section{Conservation of Australian Oryza}

Ex situ

\section{Genebanks}

Sixty-two Australian wild Oryzeae accessions are stored as seed in the Australian Tropical Crops and Forages Germplasm Centre, comprised of 54 Oryza and eight Potamophila collections (Table 2; www.dpi.qld.gov.au/ auspgris). These Oryza were collected across northern Australia and were along the known geographic spread for each species. The collections of Potamophila are from all known populations of the species and are therefore representative both genetically and geographically. The Oryza collections are from a relatively wide geographic distribution; however, the local environment is vastly different across the known geographic ranges of these species. Future targeted collecting missions need to be undertaken to actively conserve seed from the ecotypes within the geographic range of each species so that the genetic diversity of these species is appropriately conserved and available for future research and breeding activities.
Ex situ seed collections of Australian collected Oryza species are also conserved in some international germplasm collections. The two largest collections are at the International Rice Research Institute (IRRI) in the Philippines and the National Institute of Genetics and National Bioresource Project, Japan (Table 2). The IRRI collection consists of a total of 83 accessions from the three species $O$. australiensis, O. meridionalis, and O. rufipogon (http://www. irgcis.irri.org:81/grc/irgcishome.html). The collection conserved in Japan consists of a total of 84 accessions from the two species $O$. australiensis and $O$. meridionalis (http:// www.shigen.nig.ac.jp/rice/oryzabase/wild/coreCollection. jsp).

Recent DNA sequence analysis has shown that some Australian samples held in the National Institute of Agrobiological Sciences genebank in Japan as $O$. rufipogon are distinct from other $O$. rufipogon and similar to $O$. meridionalis (Ishikawa, unpublished). Further molecular analysis of plants from sites where both of these taxa are reported may clarify the distinctness of these species and the extent of any gene flow between them.

\section{DNA banks}

Genetic variation within a species has been demonstrated to be sensitive to environmental change and is a significant marker for changes in biodiversity (Forest et al. 2007). The Australian Plant DNA Bank holds DNA and associated tissues of small numbers of accessions of the Australian Oryza species (Table 2) as a reference against which genetic change in wild populations could be monitored. These samples represent materials collected in collaboration with other research groups and agencies, e.g., Australian Tropical Crops and Forages Collection and Hirosaki University. More than one individual plant per species are held and the original specimens were collected from more
Table 2 Ex Situ Conservation of Australian Species from the Oryzeae Tribe in the Australian Plant DNA Bank and as Seed Under LongTerm Conservation Conditions in the Australian Tropical Crops and
Forages Germplasm Centre, the International Rice Research Institute in the Philippines, and the National Institute of Genetics and National Bioresource Project in Japan

\begin{tabular}{|c|c|c|c|c|c|}
\hline \multirow[b]{2}{*}{ Taxon } & \multirow{2}{*}{$\begin{array}{l}\text { Australian Plant } \\
\text { DNA Bank } \\
\text { Total }\end{array}$} & \multicolumn{2}{|c|}{$\begin{array}{l}\text { Australian Tropical Crops and } \\
\text { Forages Germplasm Centre }\end{array}$} & \multirow[t]{2}{*}{ IRRI, Philippines } & \multirow[t]{2}{*}{$\begin{array}{l}\text { National Bioresource } \\
\text { Project, Japan }\end{array}$} \\
\hline & & Total & State of origin & & \\
\hline Oryza australiensis & 33 & 27 & NT 20, QLD 6; WA 1 & 34 & 37 \\
\hline Oryza meridionalis & 11 & 18 & NT 18 & 45 & 47 \\
\hline Oryza officinalis & 3 & 0 & & & \\
\hline Oryza rufipogon & 3 & 5 & NT 4, QLD 1 & 4 & \\
\hline Potamophila parviflora & 8 & 8 & NSW 8 & & \\
\hline Total & 58 & 62 & & 83 & 84 \\
\hline
\end{tabular}

$T$ Northern Territory, $Q L D$ Queensland, WA Western Australia 
than one geographical location ensuring that geographical diversity is held. Much more detailed sampling will be required to adequately represent the genetic diversity of Australian Oryza. These samples provide a central repository of DNA for genomics applications and research (Rice et al. 2006). Plant DNA banks have the ability to conserve the genetic fingerprint defining the species as well as the diversity within, and in the future, it is possible that they will act as "molecular snapshots" (Rice et al. 2008).

It is also highly desirable that the plant specimen vouchers be lodged with a recognized herbarium such as those listed in the Index Herbariorum (Thiers, continuously updated; http://sweetgum.nybg.org/ih/). Strong linkages between DNA Banks and traditional germplasm collections have merit in that they allow plant breeders and researchers to screen the DNA prior to selecting germplasm accessions for further investigation. With the recent advances in DNA sequencing and molecular analysis, the sequencing of whole genomes is an achievable short-term goal, and it is likely that DNA collections will hold the original samples from which the published sequence was derived. Linking of DNA vouchers with global positioning system data and herbarium vouchers and other data about the site of collection is desirable to add scientific value to collections.

\section{In situ}

O. officinalis is known from only two widely separated populations in remote areas of extreme northern Australia (Fig. 1). Little is known of the extent and size of these two populations and even less of the degree to which these are genetically distinct from individuals in neighboring countries to the north. In the absence of this knowledge, the conservation status of the material in Australia cannot be assessed.

The widespread distribution of the other three species in Australia (Fig. 1) indicates that these species are secure in the wild. However, the limited knowledge of the genetic diversity within and between widely separated populations suggests the possibility that the loss of local populations might be significant. These species are found both within and outside protected areas such as national parks. Novel genetic variants and even undescribed species may be present. More extensive collection and careful molecular analysis are required to ensure that valuable genetic resources are not lost before they are discovery or described.

Risks for local populations include competition with weeds and land clearing for agriculture. Grazing by livestock may damage populations. The site depicted in Fig. 4 at Abattoir Creek in Queensland illustrates a population of $O$. rufipogon that was being grazed by livestock and threatened by altered surface water flows from a nearby sugarcane plantation. Weeds were also abundant at this site.

Climate change poses a range of threats to Oryza species in Australia. Changes in rainfall intensity altering water flows may alter suitable habitats for Oryza in Northern Australia. Rising sea levels may allow salt to move further inland in some extensive wetland that currently support significant Oryza populations.

Analysis of the genetic diversity in these wild populations is required to determine the best way to manage their conservation. Genome sequencing is expected to provide a reference sequence for each species to use as basis for measuring diversity within these species.

Conservation of these populations in situ can only be assured if we have more knowledge of the distribution of diversity within populations. This will establish the need or otherwise to protect specific populations especially in the very widespread species. Effective conservation plans depend on obtaining this genetic information. Conservation in reserves would appear adequate, but view this could change in genetic variations between populations were identified.
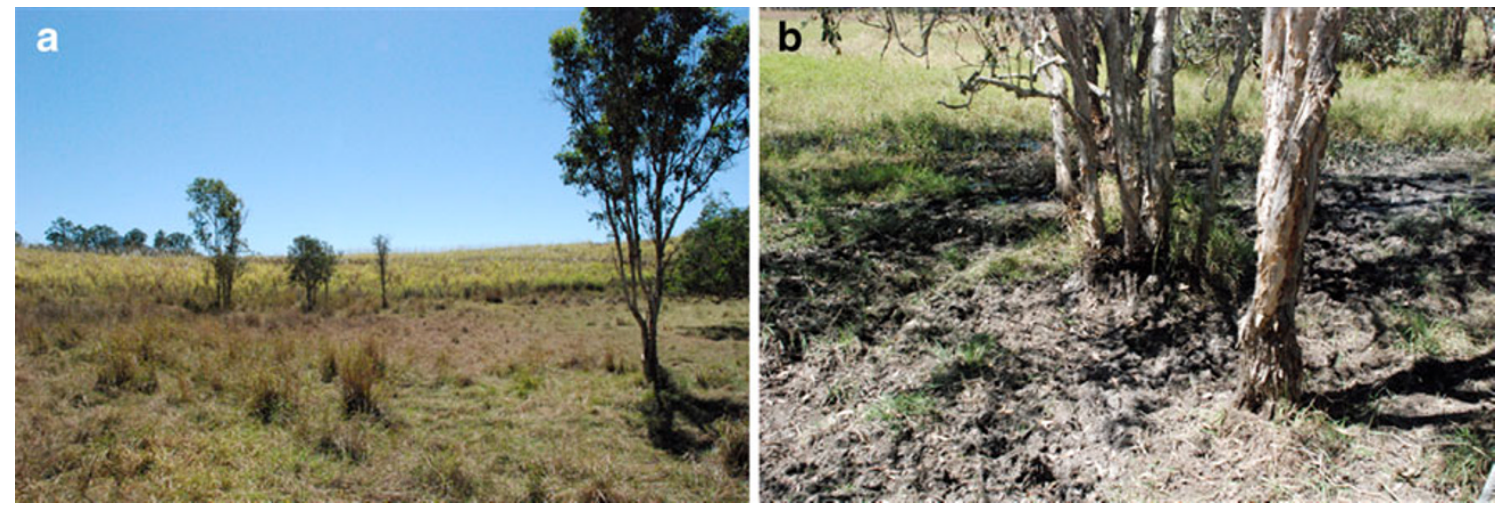

Fig. 4 Wild rice habitat $O$. rufipogon population at Abattoir Creek environmental park. a Population with adjacent sugarcane plantation nearby perennial type habitat. b Grazed $O$. rufipogon population under Melaleuca sp. at the same site in the dry season. 


\section{Utilization of Australian Oryza}

Australian rice breeding programs have made very limited use of rice outside the O. sativa gene pool. Oryza species which include the Australian Oryza have been a source of both biotic and abiotic resistance genes (Brar and Khush 1997). O. officinalis has provided genes for bacterial blight, whitebacked planthopper, and brown planthopper resistance (Brar and Khush 1997). O. australiensis has been a source and of bacterial blight resistance (Brar and Khush 1997), and brown planthopper resistance has been introgressed from $O$. australiensis into rice cultivars (Jena et al. 2006). $O$. australiensis is also a source of durable blast resistance and genes for this important trait have been incorporated into advanced breeding lines (Jeung et al. 2007; Suh et al. 2009). O. meridionalis (Sundaramoorthi et al. 2009) and $O$. australiensis have been suggested as sources of drought tolerance. O. rufipogon has been used as a source of both biotic, tungro resistance, and abiotic, acid sulfate soil, and aluminum tolerance, stress-response genes (Brar and Khush 1997; Nguyen et al. 2003; Ram et al. 2007). Quantitative trait locus analysis of $O$. rufipogon $\times O$. sativa and $O$. minuta $\times O$. sativa crosses suggests both $O$. minuta and $O$. rufipogon harbor loci which enhance yield potential in an $O$. sativa background (Xie et al. 2008). O. minuta and $O$. nivara have provided a range of disease resistance genes (Brar and Khush 1997; Gu et al. 2004); however, the presence of these species in Australia or their relationship to Australian populations is uncertain and would benefit from further collection and genetic analysis.

The wild relatives of cultivated rice are yet to provide genes for grain quality, unlike the wild relatives of cultivated wheat and tomato which have been utilized extensively as donors of quality traits (Hajjar and Hodgkin 2007). The grain characteristics of Australian Oryza have been investigated to establish their potential as domesticated food crops and to evaluate the likely impact that they might have on rice grain quality if used as genetic resources for rice $(O$. sativa $)$ breeding. The whole grain appearances of $O$ rufipogon, $O$. meridionalis, and $O$. australiensis suggest these species have potential as whole grain foods that could be consumed as alternatives to $O$. sativa (Kasem et al. 2010). The grains are generally of a similar size but have a darker appearance when compared with cultivated rice. The endosperm structure and starch granule morphology of $O$. rufipogon and $O$. australiensis was found to be similar to that of $O$. sativa (Shapter et al. 2008). However, the starch granules in $O$. australiensis were slightly smaller and the protein matrix more obvious in $O$. rufipogon.

The starch synthesis gene GBSS has been compared in $O$. rufipogon and O. australiensis (Shapter et al. 2009). The genes all showed close homology with rice and with other wild grasses with similar starch granule morphology. Genes for grain traits that have been selected by humans such as aroma (Bradbury et al. 2005) and texture and cooking time (Waters et al. 2006) have been characterized in rice using the resources of the genome sequence. The diversity of these genes can now be explored in wild relatives of rice. These species are diverse genetic resources for use in rice improvement and may be especially useful in adapting rice to future pest and diseases and to abiotic stress. The more diverged relatives of rice in the Australian flora, such as Potamophila and Microlaena, may contribute to food security by providing more radical options to adapt rice to different or changing environments and to a wider range of environments.

Despite the demonstrated value of wild rice introgressions (Ballini et al. 2007), rice breeders are often reluctant to disturb favorable linkage blocks which they have constructed over many years by crossing locally adapted cultivars with wild rice relatives. New high output sequencing and high throughput genotyping platforms now mean it is possible to obtain cross specific genome sequence. These data can be converted to molecular markers which saturate the background of both parents which then allows the background of the recurrent parent to be efficiently and quickly regained which contains very narrow introgressed segments of the wild rice genome.

The Australian Oryza are a poorly characterized but potentially very important part of the genepool for rice. The conservation of these genetic resources both in situ and ex situ requires further effort to ensure that this diverse resource remains available to support rice improvement.

Acknowledgments The authors would like to thank Peter Bannink for his assistance in the preparation of the map depicted in Fig. 1. We would also like to thank Ruaraidh Sackville-Hamilton from the Rice Genebank at the International Rice Research Institute and Nori Kurata from the National Institute of Genetics Wild rice collection for providing their ex situ Australian wild rice collection information.

\section{References}

Abedinia M, Henry RJ, Cripps-Clark S. Distribution and phylogeny of Potamophila parviflora $\mathrm{R}$. Br a wild rice from eastern Australia. Genet Resour Crop Evol. 1998;45:399-406.

Ballini E, Berruyer R, Morel JB, Lebrun MH, Notteghem JL, Tharreau D. Modern elite rice varieties of the 'Green Revolution' have retained a large introgression from wild rice around the Pi33 rice blast resistance locus. New Phytol. 2007;175:340-50.

Bradbury LMT, Fitzgerald TL, Henry RJ, Jin Q, Waters DLE. The gene for fragrance in rice. Plant Biotechnol J. 2005;3:363-70.

Brar DS, Khush GS. Alien introgression in rice. Plant Mol Biol. 1997;35:35-47.

Cross M, Waters D, Lee LS, Henry RJ. Endonucleolytic mutation analysis by internal labeling (EMAIL). Electrophoresis. 2008;29:1291-301.

Forest F, Grenyer R, et al. Preserving the evolutionary potential of floras in biodiversity hotspots. Nature. 2007;445(7129):757-60. 
Gu K, Tian D, Yang F, Wu L, Sreekala C, Wang D, et al. High-resolution genetic mapping of $X a 27(\mathrm{t})$, a new bacterial blight resistance gene in rice, Oryza sativa L. Theor Appl Genet. 2004;108:800-7.

Hajjar R, Hodgkin T. The use of wild relatives in crop improvement: a survey of developments over the last 20 years. Euphytica. 2007;156:1-13.

Jena KK, Jeung JU, Lee JH, Choi HC, Brar DS. High-resolution mapping of a new brown hopper (BPH) resistance gene, Bph 18 $(\mathrm{t})$, and marker-assisted selection for $\mathrm{BPH}$ resistance in rice. Theor Appl Genet. 2006;112:288-97.

Jeung JU, Kim BR, Cho YC, Han SS, Moon HP, Lee YT, et al. A novel gene, Pi40(t), linked to the DNA markers derived from NBS-LRR motifs confers broad spectrum of blast resistance in rice. Theor Appl Genet. 2007;115:1163-77.

Kasem S, Waters DLE, N. Rice N, Shapter FM, Henry RJ. Whole grain morphology of Australian rice species. Plant Genet Resour. 2010; doi:10.1017/s1479262109990189

Kim HR, Hurwitz B, Yu Y, Collura K, Gill N, SanMiguel P, et al. Construction, alignment and analysis of twelve framework physical maps that represent the ten genome types of the genus Oryza. Genome Biol. 2008;9:R45.

Kodela PG. Oryza. In: Wilson AJG, editor. Flora of Australia volume 44A. Melbourne: Australian Biological Resources Study, CSIRO; 2009.

Nguyen BD, Brar DS, Bui BC, Nguyen TV, Pham LN, Nguyen HT. Identification and mapping of the QTL for aluminium tolerance introgressed from the new source, Oryza rufipogon Griff., into indica rice (Oryza sativa). Theor Appl Genet. 2003;106:583-93.

Piegu B, Guyot R, Picault N, Roulin A, et al. Doubling genome size without polyploidization: dynamics of retrotransposition-driven genomic expansions in Oryza australiensis, a wild relative of rice. Genome Res. 2006;16:1262-9.

Ram T, Majumder ND, Mishra B, Ansari MM, Padmavathi G. Introgression of broad-spectrum blast resistance gene(s) into cultivated rice (Oryza sativa ssp indica) from wild rice $O$. rufipogon. Curr Sci. 2007;92:225-30.

Rice N, Cordeiro GM, Shepherd M, Bundock PC, Bradbury LME, Watson L, et al. DNA banks and their role in facilitating the application of genomics to plant germplasm. Plant Genet Resour. 2006;4:64-70.

Rice N, Kasem S, et al. DNA Banks as a resource for SNP genotyping. In: Henry RJ, editor. Plant genotyping II SNP technology. Oxfordshire: CABI; 2008.

Shapter FM, Lee LS, Henry RJ. Endosperm and starch granule morphology in wild cereal relatives. Plant Genet Resour. 2008;6:85-97.

Shapter FM, Eggler P, Lee LS, Henry RJ. Variation in Granule Bound Starch Synthase I (GBSSI) loci amongst Australian wild cereal relatives (Poaceae). J Cereal Sci. 2009;49:4-11.

Suh JP, Roh JH, Cho YC, Han SS, Kim YG, Jena KK. The Pi40 gene for durable resistance to rice blast and molecular analysis of Pi40-advanced backcross breeding lines. Phytopathology. 2009;99(3):243-50.

Sundaramoorthi J, Babu C, Ram SG. Molecular diversity in the primary and secondary gene pools of the genus Oryza. Plant Syst Evol. 2009;279:115-23.

Vaughan DA, Lu BR, Tomooka N. The evolving story of rice evolution. Plant Sci. 2008;174:394-408.

Waters DLE, Henry RJ, Reinke RF, Fitzgerald MA. Gelatinization temperature of rice explained by polymorphisms in starch synthase. Plant Biotechnol J. 2006;4:115-22.

Wheeler MA, Lee LS, Henry RJ. The reproductive biology and genetic diversity of Potamophila parviflora $\mathrm{R}$. Br. Genet Resour Crop Evol. 2001;48:483-97.

Xie XB, Jin FX, Song MH, Suh JP, Hwang HG, Kim YG, et al. Fine mapping of a yield-enhancing QTL cluster associated with transgressive variation in an Oryza sativa x O. rufipogon cross. Theor Appl Genet. 2008;116:613-22. 